\title{
Dividing Online and Offline: A Case Study
}

\author{
Ginger Zhe Jin and Andrew Kato \\ University of Maryland ${ }^{1}$
}

This draft: April 20, 2004

\begin{abstract}
This paper investigates how the Internet, as a bundle of transaction cost savings and information problems, defines the boundary between online and offline trading. Sportscards provide an excellent example: credible quality information is difficult to obtain online, but Internet auction trading offers substantial search cost savings. Moreover, the existence of professional sportcard grading offers a potential solution to online information problems, and allows us to experimentally detect the magnitude of the online information problems for ungraded cards. Set up in a general equilibrium framework, we model and test (1) the online and offline segmentation in product quality, (2) the evolution of retail outlets after the Internet came into place, and (3) the evolution of supporting industries such as professional grading and card manufacturing. Empirical evidence suggests that the introduction of new online markets produces not only quality segmentation, but also fosters the growth of an industry that helps alleviate the online information problems, and encourages the introduction of products best suited for online trading.
\end{abstract}

JEL: D40, D50, D82, D83, L10, L15.

Keywords: transaction costs, online trading, asymmetric information, general equilibrium.

\footnotetext{
${ }^{1}$ Corresponding author: Ginger Z. Jin, Department of Economics, University of Maryland, College Park, MD 20742. Email: jin@econ.umd.edu. We benefit from Tim Bresnanhan, Tom Hubbard, Raphael Thomadson, John Shea, Dan Vincent, David Reiley, Larry Ausubel, Peter Cramton, V. Joseph Hotz, Jimmy Chan, Vincent Crawford, John Rust and numerous seminar attendants. We are particularly grateful to Seth Sanders and John List for their instrumental help in developing the research. Special thanks go to eight friends who acted as our agents in purchasing baseball cards in retail markets, and numerous sportscard storeowners for their time and insights regarding the sports card industry. Excellent research assistance from Randy Alexander Moore and Krzysztof Fizyta is gratefully acknowledged. Any remaining errors are ours.
} 


\section{Introduction}

The defining characteristics of a market relate to the transaction costs present in that trading environment. These costs include (but are not limited to) finding and evaluating sellers, discovering the quality of various things for sale, and physically exchanging value for ownership of the purchased goods or services. Simultaneous existence of multiple markets for the same good may occur if those market environments have sufficiently different mixes of transaction costs. In such a situation, each market setting will attract the buyers and sellers who are particularly well suited to dealing with the costs associated with that setting.

The central question posed by this paper is: How do existing markets for a particular good adjust to the introduction of a new market setting with a radically different mix of transaction costs? In particular, we examine how widespread adoption of Internet auctions among sportscard buyers and sellers has affected the way traditional retail sportscard industries operate. While online auctions have relatively lower costs of matching buyers and sellers, they have relatively higher costs of discovering quality information about the cards for sale. In addition, online auction markets may involve higher risks of being defrauded. We capture such tradeoffs in a general equilibrium model and derive testable predictions regarding (1) the online and offline segmentation in product quality, (2) the evolution of retail stores and local card shows after the Internet came into place, and (3) the evolution of supporting industries such as professional grading and manufacturing.

Several predictions regarding the segmentation of markets in quality and participant types emerge in equilibrium. First, because buyers cannot observe cards before purchase in online auctions but can examine them at leisure in a traditional retail store, the quality of ungraded sportscards should be higher in the retail segment; this is the traditional lemons problem (Akerlof 1970, Genesove 1993). Second, buyers' inability to examine card quality before online purchase implies that use of a credible third-party signal of quality will be more valuable online, and that market participants who have invested in acquiring card quality evaluating skills will be comparatively better off in retail markets. Reinforcing this, buyers must pay first and await shipment of a card when buying online as opposed to receiving the card immediately in a retail store. The higher risk of fraud online again implies that relatively more skilled participants will choose to trade in retail markets since their costly investment in skills for identifying counterfeits, bad quality, and shady traders are rendered useless in the online environment.

Experimental results and survey data provide a preponderance of evidence that support all predictions from the model. Taking advantage of industry accepted quality guidelines, pro- 
fessional grading and authentication services, and an industry standard price guide, we directly tested the quality difference between online and offline markets via a field experiment. Specifically, we purchased the same type of ungraded cards from online and offline markets and sent them for professional certification. As expected, cards purchased online were 0.255 to 0.82 grades lower on average than retail cards. Also, a majority of the 455 retail store owners who responded to our survey said they dealt in very few or no graded cards, and about two thirds of them avoided participating in the online market. This is consistent with an observation from prior work that two thirds of all auctions online were for graded cards rather than ungraded cards. Thus more experienced buyers and sellers like retail store owners preferred to remain in retail markets, and new online markets utilized professional grading far more than traditional retail markets.

The analysis is broadened to include not only the decisions of economic agents on whether to stay or move into the new market setting, but also the decisions of secondary industries. Data presented in this study show that sportscard manufacturers adjusted the parameters of their products to cater to the new online market's features. Also, upon the opening of the new online market, the demand for professional grading soared, resulting in a downward shift of the average quality of graded cards and inviting numerous entries into the professional grading business. Consistent with our model, these changes are in place to either take advantage of the search cost savings from the online markets or to minimize the informational problem introduced by online trading.

We would like to make two contributions to the existing literatures. The first is to highlight the information disadvantages that exist online, and to enhance understanding of how they affect market outcomes (Bajari and Hortacsu (forthcoming)). Secondly, most existing studies focus on the demand side, identifying which types of buyers are more likely to shop online and how much less those buyers pay than their offline counterparts ${ }^{2}$ Recent studies extend to sellers' pricing strategy and price competition among online/offline sellers. ${ }^{3}$. In complement to both literatures, we view the online-offline segmentation as an equilibrium phenomenon, paying more attention to quality differences, the sorting of sellers, and the impact of segmentation on supporting industries.

The rest of the paper is organized as follows. Section 2 provides a brief review of sports

\footnotetext{
${ }^{2}$ See Goolsbee 2000, Clay et al. 2001, Goolsbee 2001, Brown and Goolsbee 2002, Scott Morton and Zettelmeyer 2001, and Scott Morton et al. 2004.

${ }^{3}$ See Zettlemeyer 2000, Ellison and Ellison 2001, Ellison and Ellison 2003, Chevalier and Goolsbee forthcoming, and Scott Morton et al. forthcoming
} 
card markets, followed by a general equilibrium model in Section 3. Testable predictions derived in Section 3 are tested one by one in Sections 4-6. Specifically, Section 4 uses a field experiment to test the boundary between online and offline markets, and conducts a nationwide telephone survey to detect the evolution of retail sports card stores. Section 5 presents empirical evidence regarding changes in the population of graded cards. Section 6 documents a dramatic change in card printing. Alternative explanation and conclusive remarks are offered in Section 7.

\section{Market Overview}

Given the long history of baseball, the sportscard market is dominated by baseball cards. Moreover, all market features described below are identical for baseball, football and basketball cards. For these reasons, we use sportscards and baseball cards interchangeably.

Each year, card companies design and print sets of cards depicting players and events from the previous season. Once the print run of a particular set has been completed, the supply of each distinct card in the set is fixed. ${ }^{4}$ The value of a particular card depends on its scarcity, the player depicted and the condition of the card. By card condition, we mean the physical condition of the edges, corners, surface and centering of the printing. To track card condition, people often use a 10-point scale. For example, flawless characteristics (even under microscopic inspection) will rate a perfect 10 while obvious defects to the naked eye like minor wear on the corners of the card might bring a corners grade to 7 . The card's overall grade is computed off all four characteristics.

Figure 1 shows interest in cards as a valuable commodity grew dramatically during the 1980s. Amid concerns over authenticity, Professional Sports Authenticator (PSA) began offering grading services in 1987. Beckett Grading Service (BGS) and Sportscard Guaranty Corporation (SGC) entered the professional grading market in 1999. As of 2002, PSA and BGS remain the largest and most respected of the existing 10-15 grading services. Because professional grading is voluntary and costs 6 to 20 dollars per card ${ }^{5}$, this practice divides the market into two groups: graded cards and ungraded cards. For graded cards, buyers and sellers alike are willing to accept PSA, BGS and SGC grades as the "true" grade of a card's condition. ${ }^{6}$ Graded cards are

\footnotetext{
${ }^{4}$ The exact number of copies printed for a specific card is regarded as an industry secret, except for the insert cards discussed later in Section 7.

${ }^{5}$ Depending on package size and turnaround time, but independent of the actual grades received.

${ }^{6}$ Jin, Kato and List (2004) conduct two field experiments to test the grading practice of PSA, SGC and BGS, and compare them with regular buyers/sellers in the sportscard markets. They find that all professional graders
} 
encased in plastic and sealed with a sonic procedure that makes it virtually impossible to open and reseal the case without evidence of tampering. The casing indicates the grading service, grade received, and a bar code with serial number that identifies the particular copy of the card. Anyone with Internet access can go to the grader's web site and verify the card's grade by serial number. Figure 2 gives two examples of baseball cards, one is an ungraded 1989 Upper Deck \#1 Ken Griffey Jr.Rookie, and the other is a PSA-graded 1985 Topps \#401 Mark McGwire Rookie.

Traditionally, single sportscards were traded through retail stores or local card shows. Virtually all retail stores are small independent family-run businesses involving very few employees. Acting as a middleman, a typical storeowner buys single cards from customers, and sells them to other customers. Since there are only about 10 to 20 card stores in each major metropolitan area, collectors sometimes turn to local card shows as an alternative. Local card shows are often held at shopping malls and convention centers, bringing anywhere from five to more than two hundred dealers to one location. Dealers at these shows pay a table fee, and buyers are often charged an admission fee.

Online trading of sports cards did not take off until 1998, when eBay provided the first standardized, user-friendly auction site where individual sellers and buyers could meet and transact conveniently. Ever since eBay went public on September 24, 1998, eBay has always been the most popular online place to trade single baseball cards. ${ }^{7}$ Figure 1 summarizes this time line and contrasts it with the history of baseball cards.

\section{Theory}

\subsection{Assumptions}

Consider a large number $(\mathrm{N})$ of sellers, each endowed with a random copy of quality $q_{j}$ for the same card. $q_{j}$ is private information to the seller. All sellers put zero value on their card and would like to sell, regardless of their endowment's quality. Selling in retail markets involves transaction costs $c_{t}$, which is an increasing function of the card's true quality because it is harder to find buyers willing to pay full value for a high quality card. Selling in eBay involves zero provide valuable information to the market, and BGS, the latest entrant of the three graders, is most consistent. That explains why we use BGS in our field experiment.

${ }^{7}$ Based on our interviews with over 30 sports card stores and a phone survey of 1213 sports card stores listed in Yahoo! Yellow pages. Section 6 describes the survey in more detail. See Lucking-Reiley (2000), Melnik and Alm (2002), and Resnick and Zeckahuser (2002) for the description of eBay auction settings. 
transaction costs. Regardless of where a card is sold, it is assumed that there is no default and that the seller always delivers an authentic card.

There are $\mathrm{M}(M>N)$ risk-neutral buyers who all put positive value on the first copy of the card they buy and zero on any subsequent copies. ${ }^{8}$ Each buyer has a taste for quality $\theta_{i}$ which is only observable to buyer $i$. Buying a copy of quality $q$ at price $p$ allows him to derives utility $U_{i}(q)=\theta_{i} q-p$. Over the whole population, $\theta, h$ and $q$ independently conform to publicly known distributions. Both sellers and buyers are price takers.

The game proceeds as follows. At stage 0, each seller receives a random endowment and observes its quality. At stage 1, each seller decides whether or not to send his card for grading. If he does, he pays a constant grading cost $c_{g}$ and the grader seals his copy in a tamper-proof plastic case marked with a grade equal to the true quality. At stage 2, if the card has been graded, the owner can sell the card as graded or crack open the case and sell it as ungraded. If he does not send the card for grading, he can only sell it as ungraded.

Regardless of whether the card is graded or ungraded, the sale may occur in either retail or online markets. This defines four market segments - retail ungraded, online ungraded, retail graded and online graded. If a card is sold as graded, both the seller and the buyer observe the true quality. If a card is sold as ungraded in the retail market, both the seller and the buyer observe the true quality as well because the buyer can examine the card carefully before purchase. 9 In contrast to this, if a card is sold online as ungraded, the seller observes the quality but buyers observe nothing. ${ }^{10}$ Note that online ungraded is the only market segment that features asymmetric information for buyers and sellers.

The equilibrium satisfies three conditions: on the demand side, if buyer $i$ decides to buy, he will buy a copy that maximizes his expected utility from purchase. On the supply side, seller $j$ will sell his endowment in the market segment that gives him the highest return net of total cost associated with that segment. In particular, he will grade his copy if and only if the expected return from grading is no less than the expected return from not grading. In equilibrium, demand equals supply in all market segments. If two cards are offered in different

\footnotetext{
${ }^{8}$ Similar results arise if we allow individuals to be sellers and buyers simultaneously. Here sellers and buyers are assumed to be separate groups of people, purely for simplicity.

${ }^{9}$ The perfect observability of card condition is a simplified assumption and not critical to the model. Similar results hold when we only allow individuals to receive a noisy but unbiased signal of the card's true quality.

${ }^{10}$ In Jin \& Kato (2004), we allow online sellers to make claims of quality for ungraded cards and present empirical evidence regarding this feature. Adding this feature to the model does not result in any qualitative changes in any predictions tested in this paper.
} 
market segments but appear identical to buyers, their prices must be equal.

\subsection{Equilibrium Properties}

There are unique or multiple equilibria, depending on whether sellers (and the buyers in the ungraded retail sector) obtain perfect or noisy information on ungraded card quality. In either case, the following equilibrium properties hold, and so do the theoretical predictions relevant for our empirical tests. To save space, our discussion focuses on equilibrium properties. Mathematical proofs are available upon request.

First of all, price must be an increasing and convex function of buyer-expected card quality because buyers with stronger tastes for quality always prefer better quality. Second, all graded cards must be traded online. This is because once grading cost is sunk, there is no informational gain by paying $c_{t}$ to sell in the retail market. Third, graded cards will never be cracked open because sellers observe the true quality of and therefore perfectly predict the returns to grading their endowments.

Ruling out the retail graded segment, the other three segments - online ungraded, retail ungraded and online graded - will be sorted by quality. Given $c_{t}, c_{g}$ and price schedules in all segments, seller $j$ 's best strategy consists of two thresholds $q^{l}$ and $q^{h}$. If the quality of his endowment exceeds $q^{h}$, he will have it graded and sell the graded copy online. If the endowment quality is between $q^{l}$ and $q^{h}$, he will sell it as ungraded in the retail market. Otherwise, the copy will be sold online as ungraded. The above discussion suggests three testable predictions, as depicted in Figure 3:

- Assuming away default risk ${ }^{11}$, all graded cards should be traded online; and $q_{\text {gradedonline }}>$ $q_{\text {ungradedretail }}>q_{\text {ungradedonline }}$. This predicts the three market segments depicted in Figure 3.

\footnotetext{
${ }^{11}$ Expanding the model to include sellers who sell counterfeit cards or deliver nothing at all will not change any fundamental conclusions; only the exact values of the thresholds separating the market segments will change. This is because buyers and sellers can adjust their expected values in each segment to include the likelihood of each type of fraud multiplied by the actual value of fraudulent outcomes (we believe zero is an appropriate value for fake goods). Consider the upper threshold $q^{h}$. Whether it is higher or lower would depend on the online graded default rate and the traditional retail counterfeit rate, but we do not expect that the introduction of fraud would somehow reverse the order of the two segments in quality; graded cards online will still be the higher quality cards.
} 
- All graded and some ungraded cards shift from retail to online markets. As a result, the existing retail market shrinks, even though the overall trading volume of the combined online and offline markets increases due to transaction cost savings online. Figure 3 illustrates this prediction by the two arrows pinching the retail sector and the opening of online trading at both ends of the quality spectrum where no prior retail trading occurred.

- Graded cards are traded online exclusively and their trading volume should increase after the emergence of widespread trading online. ${ }^{12}$ The Internet causes $q^{h}$ to shift down, driving graded card population growth, especially at the lower end of the graded quality distribution. This is shown in Figure 3 by the expansion of the quality range over which cards are graded.

\section{Market Segmentation and Retail Shrinkage}

This section tests the first two predictions. The prediction on market segmentation can be decomposed into three parts: first, ungraded cards traded in retail have better quality than ungraded cards traded online. This is the typical "lemons problem." 13 Second, unless there is a huge noise in the naked-eye evaluation of card quality, most graded cards should have better quality than ungraded cards. Third, the majority of graded cards should be traded online rather than in retail. The third component is directly related to the second theoretical prediction: the retail sector would shrink because most graded cards and some ungraded cards shift from retail to online.

We first present experimental evidence regarding the quality segmentation and then describe a telephone survey of sports card stores to compare the volume of graded cards traded online and offline. The telephone survey, as well as the list of sports card shows from historical Beckett guides, addresses the shrinkage of retail market.

\footnotetext{
${ }^{12}$ The model assumes perfect observation of quality in retail markets which implies zero demand for grading before online markets exist. In reality, evaluation of card quality depends on buyers and sellers' ability to judge card condition by the naked eye. If buyers and sellers in the retail market only receive a noisy but unbiased signal of quality, $q^{h}$ exists even without the Internet because grading is valuable for resolving the uncertainty. The other equilibrium properties are unaffected by the addition of uncertainty to the model.

${ }^{13}$ If we assume rational expectation. When that assumption is violated, the quality difference implies the sum of consumer frauds and the lemons problem. See Jin \& Kato (2004) for details.
} 


\subsection{Quality segmentation}

\subsubsection{Experimental Design}

Because information asymmetry is most severe for ungraded cards, our field experiment deals with ungraded cards only. Specifically, we purchased ungraded cards from both retail and online markets, and sent them for professional grading. This gave us a direct and objective measure of the true card quality. The purchasing and grading procedures were designed to mimic actual practices in both markets. After consulting with over 20 local dealers, we focused on five types of rookie cards - 1989 Upper Deck Ken Griffey \#1, 1982 Topps Cal Ripken \#21, 1985 Topps Mark McGwire \#401, 1993 SP Derek Jeter \#279 (foil), and 1994 SP Alex Rodriguez \#15 (foil). To avoid any changes in card value due to players' performance, we restricted our purchases to the off-season of baseball from December 8, 2001 to March 18, 2002. Retail store interviews suggested that an overwhelming majority of customers are adults and they only pay attention to cards of near-mint 7 or better quality. For this reason, both our retail and online purchases targeted cards that appeared to have such "collectible quality" given the information available at the time of purchase. ${ }^{14}$

Retail Purchases We considered all cards from accessible retail stores or local card shows in 11 metropolitan areas, and those cards were purchased if they were not disqualified by the above "collectible quality" rule. These areas were picked to represent both cities with and without Major League Baseball franchises. We used Yahoo! yellowpage listings to identify sports card stores in each of these 11 markets. In Philadelphia ${ }^{15}$, Baltimore, and areas surrounding Washington D.C., we personally visited every retail store that carried any one of our five targeted cards plus the regional sports card show in Ft. Washington, PA during March 1-3, 2002.

Purchases from Chicago, San Jose, Denver, Dallas, Los Angeles, San Diego, Tucson and Detroit were completed by male agents, age 25-35, who held at least a master's degree from a U.S. graduate school and were not active collectors at the time of purchase. To make sure every agent had the same minimum level of knowledge about baseball card markets, we sent a 21-page buyer instruction guide. This package provided step-by-step directions on locating and evaluating cards as well as procedures for negotiating prices with store owners. We also devoted sections to educate our agents on the basics of baseball cards and grading criteria that PSA

\footnotetext{
${ }^{14}$ For retail purchases, we examined the PSA and BGS grading standards and disqualified any cards that had at least one defect consistent with a PSA or BGS grade below 7. For online purchases, we ruled out all online auctions that mentioned specific defects that would have disqualified them from our retail purchases.

${ }^{15}$ including surrounding suburbs in Pennsylvania and New Jersey
} 
and BGS use to evaluate cards. To further clarify grading criteria, sample cards from the same sets as our targeted five cards were included with a magnifying glass and our comments on card defects. Follow-up phone calls to our agents were made to ensure the buying instructions were well understood and followed. Agents shipped all purchases to us using methods recommended by Beckett. Overall, we obtained 126 cards from the retail markets.

Online Purchases Online purchases were designed for two purposes: for comparison with retail purchases, and to obtain a better understanding of the online market. Before the experiment, we watched the eBay market for seven months and found that seller claims of ungraded card quality play an important role in auctions. In light of this observation, we purchased ungraded cards online in two groups so that the sellers of one group claimed systematically higher quality than the sellers in the second group. Experimental results regarding these two groups of online purchases are reported in a companion paper (Jin \& Kato (2004)). The primary focus of this paper is to compare online and retail purchases, but it is based on the same experiment, so we present all details of the experimental design. Later on we explain why buying two groups of cards online does not impair the online-offline comparison.

Each week from December 8, 2001 to March 18, 2002, we searched for active auctions as of the Saturday of that week and ranked the auctions by seller-described card condition. For those cards that were claimed "nice" or "perfect" without any specific grade suggestion, we treated them as nearmint-mint (8) based on the fact that Beckett guides always quote same prices for an ungraded nearmint-mint card and a card graded 8 . This practice was further confirmed by our market watch data, which suggested that the bidding frequency on these cards were between those claimed 7 and those claimed $9+$. The ranking process suggested that the typical supply of a particular type of ungraded single card consisted of three groups: One group of sellers indicated specific defects about the cards they were selling; a second group claimed their cards were of grade 7 or 8 quality or made no claims; the third group claimed their cards were of mint 9 or gem mint 10 quality. Because the first group is disqualified from a serious collector's point of view, our experiment focused on the latter two groups.

To sample both groups, we bid on the best-ranked and median-ranked cards after ruling out the disqualified auctions, In case we lost either one, we bid on and purchased the card ranked immediately below it. Given the clustering of seller claims, the perceived difference between the primary and backup cards were negligible. To further guarantee that every copy we purchased would be sold regardless of our presence, we restricted our bidding to the last five minutes of the auction and did not bid on a card if it had not attracted any bid by the time we were ready 
to bid. 16

To ensure winning our targeted auctions, we deliberately overbid. However, we could not bid outrageous amounts because this might distort the market if someone realized we were employing this strategy and used a shill to bid us up. Therefore, we varied our bidding strategy by adding 10-15 dollars above the leading bid. Since eBay buyers tend to "snipe" towards the end of the auctions (Roth and Ockenfels(forthcoming), Bajari and Hortacsu (2003)), sometimes we were outbid by a very small amount in the last 5-10 seconds and we did not have time to "snipe" back. Due to this technical difficulty, we lost 14 cards, 6 of which were best ranked. Since all the lost bids were made up with backup auctions and the loss was quite balanced between the two rank groups, we believe sample selection is not a big issue. As shown below, professional grading suggests that the highest reported professional grade is very similar across the two groups. So even if we were subject to the winners' curse, it should not affect our conclusion regarding the relative quality differences between the two groups.

Because the Jeter and the Rodriguez were extremely hard to find in retail markets for the procedure outlined earlier in this paper, we stopped purchasing them online after February 3, 2002. For weeks after February 3, we doubled our online purchases for the other three cards. In total, we paid for 107 cards online and received 96 of them before April 2, 2002, the date when we sent our purchases to BGS for professional grading. Of the remaining 11 cards, 7 were received after April 2, 2002 and the other 4 were never received. These 7 late cards were graded in the second round. Because including or excluding these 7 late cards does not affect our conclusion in any significant way, all results reported in this paper are conditional on the cards graded in the first package. ${ }^{17}$ We chose BGS over the other grading companies because

\footnotetext{
${ }^{16}$ As stated in eBay policies, a completed auction constitutes a legally binding contract. It is possible that sellers and auction winners may communicate after the auction ends and mutually agree to terminate the contract; there is no data for or against this conjecture. Even if such termination occurs, our findings will be unbiased as long as claims of quality are not systematically correlated with contract termination. An extreme case would be to assume that the only other bidders we observe in auctions with high claims are actually shills. If we were truly the only non-shill bidder, then some cards we purchased would not have otherwise been sold. But, since listing an item is costly, sellers using shill identities must expect that someone will eventually spring their trap. Therefore, it is reasonable to assume that real bidders exist and these items will be sold sooner or later.

${ }^{17}$ Of the 7 late cards, 3 were best-ranked and 4 were median-ranked. Including these 7 cards will reduce the likelihood of fake in our online purchases from 0.11 to 0.1028 . Conditional on authentic deliveries, including these 7 cards will reduce the quality difference between retail and online purchases from 0.255 to 0.227 grade, which is still significant at $98 \%$ level. Some store owners are concerned that grading companies may give better grades to cards sent in large packages. In order to rule out any potential grading discrepency between the two rounds, we choose to exclude the 7 late cards from the reported tables. Should there be any grading bias, it should be the same for cards sent in the same package and therefore does not affect any comparison reported in this paper.
} 
BGS uses the most detailed grading scale (1 to 10 with half grade increments) and is the only major service that provides sub-grades by centering, corners, edges and surface.

\subsubsection{Experimental Results}

Table 1 reports graded card quality for all online and retail purchases. In theory, if we assume away default and counterfeit risks, we would still expect the online ungraded market to suffer from a lemons problem. Note that we purchased two rank groups of cards from the online segment, but all qualified cards from the retail market. The different buying strategies may introduce some sample selection bias. However, as Jin \& Kato (2004) described, the online cards that would attract serious collector attention fell into either a group claiming 9 or 10, or a group claiming 7-8 or nothing. In this sense, our sampling of two rank groups does not miss the main body of the market.

Nevertheless, since we sampled equal number of cards per week from each rank group, we imposed an implicit relationship between trading probability and ranks in seller claim, which might not be market-representative. Fortunately, as reported in Jin \& Kato (2004), the systematic method by which we bought cards online has been shown to only overstate the sampling of fraudulent auctions. Once we condition on authentic and delivered cards, the true quality is uncorrelated with seller claims. Therefore, even if we may have over sampled cards with high seller claims (which turned out more likely to be fraudulent), the average quality of authentic and delivered cards is still representative of all real ungraded cards that would be sold in the current online markets. In the absence of undelivered and counterfeit cards, the quality difference from our online and retail purchases should provide an approximation of the lemons problem. Since online markets in fact involve both higher default and counterfeit risk, our results based only on authentic and delivered cards understate the true quality difference between online and offline markets.

Figure 4 depicts the true quality distributions for both our retail and online purchases. As expected, the overall grade distribution of online purchases has more weight at the lower end. 18 Based on the full sample of real purchases, the card quality is 0.82 grades lower in eBay than in retail markets, which is statistically significant at the $99.9 \%$ confidence level. This estimate includes not only the lemons problem, but also default and counterfeit risks by assigning a

\footnotetext{
${ }^{18}$ Because our agents may not have incentive to search the local retail market as intensively as we did, they may have purchased systematically lower quality of cards. This would tend to bias our retail card quality downwards and therefore our approach will provide a conservative estimate of the lemons problem.
} 
grade of zero to any transaction in either market that turned out to be fraudulent. Excluding the 11 undelivered or counterfeit cards from eBay purchases and 4 counterfeits from the retail markets, the quality difference drops to 0.255 grades but is still significant at the $98 \%$ level. This second estimate is solely an estimate of the lemons problem. We further test if this difference is attributable to outliers by examining the medians and the whole distribution instead of means. Results are similar, strongly confirming that the eBay and retail card qualities are systematically different. ${ }^{19}$ To evaluate the lemons problem, we map quality into value by using Beckett "low" book prices. Given the average quality of authentic cards is 7.586 in retail and 7.331 in online markets, we find the 0.255 grade quality difference accounts for a $\$ 2.05$ difference in average value. The quality difference is statistically significant at the $98 \%$ level, but due to large price dispersion, the difference in average value is not statistically significant.

Jin \& Kato (2004) report from the eBay market watch that $88 \%$ of online graded cards are graded 8 or above. According to Beckett price guide, the value of a card graded 8 often doubles the value of a card graded 7 . Combined these facts with our experiment results, it is clear that most graded cards traded online are significantly better in quality than ungraded cards in both retail and online sectors. This again confirms the theoretical prediction on the quality segmentation between graded and ungraded cards.

\subsection{Online and Offline Trading of Graded Cards}

We now turn to test the prediction that graded cards should be all traded online. The market watch in Jin \& Kato (2004) already demonstrated the fact that two thirds of cards traded online are graded cards. This subsection presents evidence regarding the trade of graded cards in retail markets.

To locate sports card stores, we used the Yahoo! Yellow pages listings for all 27 U.S. metropolitan areas with Major League Baseball franchises. Yahoo! Yellow pages obtains business listings from BellSouth and InfoUSA. A leader in the business information industry, InfoUSA claims to have databases of 14 million businesses compiled from 5000 white/yellow pages and hundreds of other sources. InfoUSA is also the only company of this kind that verifies every entry in the database by telephone at the time of the first listing. Although it is free for any business entity to list itself in InfoUSA database, significant effort is required to be unlisted.

\footnotetext{
${ }^{19}$ Given the fact that our retail purchases may involve an agency problem, a regression of true quality on an agent dummy and a full set of card identity dummies suggests that the lemons problem may be as large as 0.329 grades if we had made all retail purchases by ourselves.
} 
Since InfoUSA went public in 1997 and Yahoo! went public in 1996, we believe the listings in Yahoo! Yellow pages were a comprehensive cumulative database that contained a majority of all sports cards stores in business anytime after $1997 .{ }^{20}$ For completeness, we also called listings from areas without MLB franchises such as Alabama, North Carolina, South Carolina, Southern Maryland (other than Baltimore) and Northern Virginia.

A telephone survey of all sports card stores with listings was conducted to capture the identity and age of sports card stores still in business, the prevalence of stores dealing in graded cards, and the involvement of stores in online trading. Of the 1387 listings, we ruled out 174 that are obviously not sports card stores, such as "Flower4u". Of the remaining 1213 listings, another 216 turned out to be businesses other than sports card stores. The remaining 997 entries consisted of $455(46 \%)$ that were still in operation, $542(52 \%)$ that did not answer and were presumably out of business, and $17(2 \%)$ who dealt with sports cards only through the Internet or by mail order.

Of the 455 sports card stores still in business, we asked each one if they had a graded 1990 Leaf Sammy Sosa rookie card in their store. ${ }^{21}$ Just 25 stores even had one, and only 7 of those 25 shops had two or three. Regardless of whether they carried a graded Sosa card, we asked each shop if graded cards were sold there at all. 448 out of the 455 stores answered this question, and $64.73 \%$ said they dealt in very few or no graded cards. Only $8.26 \%$ responded that they had at least one display case of graded cards in their stores.

303 of the 455 stores did not participate in online trading at all. Combined with the facts that two thirds of the cards in our online auction market watch were graded and there existed more than 1.2 million graded cards by mid-1999, this means that most stores were not participating in the very market where thousands of graded cards are sold. Thus, it is not surprising that very few stores engage in substantial trading of graded cards. Another explanation is that, most retail storeowners are very experienced in card dealing and therefore are likely to have a comparative advantage in identifying good ungraded cards from bad ones on inspection. Since this ability is most rewarded in the retail ungraded sector, it encourages retail storeowners to specialize in this sector.

\footnotetext{
${ }^{20}$ Rysman (2004) finds a network effect in the Yellow Pages market, so it is in the interests of each local Yellow Pages publisher to produce as comprehensive a directory as possible; the Yahoo! Yellow pages listings are based on a database combining thousands of such directories. Bresnanhan and Reiss (1991) also use yellow pages as the main data source to analyze market structure.

${ }^{21}$ The 1990 Leaf Sammy Sosa is a popular rookie card, with at least 20 listings traded on eBay every week. We asked about the Sosa instead of any of the five cards under study because we did not want to give store owners an impression of a demand increase for any of the five cards and therefore contaminate the market indirectly.
} 


\subsection{Retail Shrinkage}

Our interviews of local store owners reveal many anedoctal stories suggesting a sharp decline of sports card stores during 1990s. As shown above, this phenomenon is confirmed in our telephone survey. Ruling out the Yahoo! store listings that are probably not sportscard stores, we find that $53.4 \%$ of the 997 stores have gone out of business since 1996. This is much higher than the $31.7 \%$ termination rate for all small businesses from 1996 to 2000 as reported by the Small Business Administration. ${ }^{22}$ Admittedly, yellow pages have more measurement errors than the Census of small business and the bias is probably towards an overestimation of retail shrinkage. But this is the best data that distinguish sportscard stores from other sporting goods retailing. 23 The yellow page data at least suggests that the termination rate of sports card stores is unlikely to be fully explained by the typical entry and exit frequencies of small businesses.

Another obvious alternative explanation for the decline of sports card stores is a decline of the popularity of baseball, as local retail store owners unanimously agreed that about half of all retail stores opened since the baseball strike in 1994 have closed for business. However, the official attendance statistics from Major League Baseball as depicted in Figure 5 suggests slow but steady growth in average attendance from 1995 to 2001. By contrast, the corresponding figure for TV ratings (Figure 6) shows a slight decline of the World Series audience from 1995 to 2001. To determine the relative importance of these two figures, we consulted card dealers. We learned that sportscard demand is mostly driven by hard-core sports fans who regularly attend games, rather than casual fans whose baseball interests are limited to the annual championship. Based on this understanding, game attendance is probably a better measure of baseball popularity relevant to sportscards. Regardless of whether one believes television ratings or park attendance is the best barometer for measuring the sport's popularity, we do not see the steady drop in popularity necessary to explain the persistent decline of the retail sportscard industry during the post-strike period.

The steady growth of baseball game attendance is inconsistent with the age distribution of the 414 surviving sports card stores who reported years of operation in our phone survey (Figure 7). The large number of stores that have been in operation from 9-12 years is indicative of the strong popularity of baseball prior to the strike. The dropoff of stores aged 5-8 years

\footnotetext{
${ }^{22}$ According to Small Business Economic Indicators 2000 at http://www.sba.gov/advo/stats/sbei00.pdf, there were 8,414,906 small business firms in the U.S. that existed at least some of the time between 1996 and 2000 , of which 5,750,600 survived by the end of 2000 . This implies a $31.7 \%$ termination rate.

${ }^{23}$ Another data source is County Business Pattern conducted by the Census Bureau. Unfortunately, it pools sportscard stores with retail units of sports equipment, sports apparel, etc.
} 
could be due to a lower number of new startups following the strike. However, if the popularity of baseball has experienced steady recovery since 1995, we would expect there to be a higher number of new stores opening in recent years. Assuming a constant survival rate, there should be a higher number of surviving stores 0-4 years old than 5-8 years old. Figure 7 shows the exact opposite trend, with fewer stores ages 0-4 despite higher recent popularity of the sport.

Similar time patterns apply to card shows. Using the monthly show calendars reported in the back of the Beckett guides from 1987 to 2001, Figure 8 tracks the number of card shows held nationwide each month. The period of strongest performance in retail markets in the form of card shows is during 1990 to 1993, corresponding to the large number of retail stores aged 9-12 years. Similarly, the number of card shows per month experienced a sharp and sizable drop immediately following the player strike in July 1994 and continued to decline along with retail stores through 2001 despite a recovery in popularity signaled by fans returning to the stadiums.

The model in Section 3 predicts that the introduction and expansion of online trading could generate a decline of retail trading. While baseball attendance gives some indication that the popularity of baseball was moving in the opposite direction of the retail sportscard industry's fortunes, the popularity of a sport is difficult to pin down. One way to strengthen the analysis is to observe other aspects of the sportscard market that should rise or fall with the popularity of the sport. Thus, we present data on the related sportscard grading and printing industries that serve to make distinctions between the alternate explanations. Rising demand for professional grading and expanded supply by card printers, along with a rise in retail stores, would imply rising baseball popularity. On the other hand, falling demand for grading services and contraction of supply by card printers along with retail decline would imply falling baseball popularity. What is critical to any popularity-driven explanation is that all three indicators of success (retail markets, grading services, and printing operations) must move together. For our online markets explanation to the various phenomena to work, we expect a mixed set of observations: retail decline but rising demand for grading and an expansion in card printing.

\section{Growth of Professional Grading}

The model predicts that transaction cost savings online should generate two changes in the demand for professional grading as the graded transactions shift online: first, the graded card population should grow substantially after the arrival of the Internet; second, the Internet causes a relative increase at the lower end of the quality distribution of graded cards. 
To test the first prediction, Figure 9 tracks the growth of PSA's graded populations for sports cards from 1995 to 1999 as reported in PSA's parent company's prospectus. ${ }^{24}$ PSA was the only professional grader in the market before 1999, so this history captures the growth of the entire grading market before and after the rise of online trading in 1998. Figure 9 shows that the volume of new grading activity in sports cards remains relatively low until after 1998, experiencing a nearly five-fold increase from 1998 to 1999. This may even understate the growth in grading activity because competitors BGS and SGC opened for business in 1999.

Figure 10 further clarifies the timing coincidence of online trading and professional sports card grading growth. The date of eBay's Initial Public Offering is used as a benchmark date to gauge the prevalence of online trading. The grading population growth rate rose slowly with the introduction of eBay in 1995, accelerated as eBay approached its IPO, and further accelerated following the date eBay became a public corporation. ${ }^{25}$ The slight slowdown of PSA grading activities in the third quarter of 1999 may be explained by the entrance of BGS and SGC as competitors. The above phenomena are certainly unexplainable by the slight increase of PSA grading cost over time.

To test the second prediction, we compare the distribution of grades in the cumulative PSA population in 1997 and 2001. Information on the 1997 PSA population was taken from a Grading Population Report published by PSA in January 1998. Population information for 2001 was obtained from PSA's online population database on December 15, 2001. For both of these time periods we recorded the grade distribution for all 194 cards with at least 100 graded copies in the January 1998 report ${ }^{26}$. In rare cases, PSA provides qualified grades, which are difficult to convert into unqualified grades. ${ }^{27}$ For this reason, cards with qualified grades are excluded from the analysis of the distribution shift.

To take advantage of the fact that we tracked a matched sample of distributions for each

\footnotetext{
${ }^{24} \mathrm{PSA}$ is a subsidiary of Collectors Universe, a public company traded under the symbol CLCT since October 1999.

${ }^{25}$ eBay was established in 1995. According to its prospectus filed in August 1998, eBay net revenues were $\$ 372,000$ for the entire year of 1996 , and grew to $\$ 1.67$ million in the first half of 1997 and $\$ 4.09$ million in the second half of 1997. In the six month leading up to its public initial offering, the net revenues reached $\$ 14.9$ million.

${ }^{26}$ The sole exception is the 1993 SP Derek Jeter, which only had 75 graded copies in 1997.

${ }^{27}$ Instead of lowering the grade of a card with one relatively significant flaw, PSA will sometimes assign the higher grade with a qualifier. For example, if a card meets all of the requirements for grade 9 except in centering, PSA may give that card a grade 9 plus an OC qualifier indicating the card is not as well centered as a grade 9 card usually is. These qualifiers account for roughly $7 \%$ of the current population. Including or excluding these qualifiers produce very similar results.
} 
of 194 cards over time, we perform a t-test of equal means for each card. For 187 of the 194 card distributions, the test rejects the hypothesis of equal mean grades in 1997 and 2001. A Wilcoxon rank-sum test rejects the hypothesis of identical grade distributions for 189 of the 194 cards. Equal medians are rejected for 183 of the 194 cards as well. ${ }^{28}$ These results overwhelmingly suggest that there is a significant shift of grade distributions toward lower quality over time. Figure 11 shows graphically the shift in distribution for the 1989 Upper Deck Ken Griffey, Jr. card, the most frequently graded card in the PSA population. There were 43,455 graded copies of 1989 Upper Deck Ken Griffey Jr. as of March 17, 2002, as opposed to just 1,861 in 1997.

We consulted local store owners and obtained two alternative explanations for the downward shift of average grades in the PSA grading population. First, the for-profit professional grader may be stricter for newly submitted copies of cards that already have a large graded population. Second, over time the professional grader may become stricter at the high end, regardless of the existing graded population. Both policies would tend to hold down the number of cards with high grades, increasing the market value of any card with a high grade. This may be desirable for a for-profit grader if the extremely high value of cards with the best grades is what attracts greater demand for grading services in the future.

We test the first alternative explanation by regressing the t-statistics we derived from the comparison of equal mean grade from 1997 to 2001 on population size as of 1997 for each of the 194 cards. While the population does have a weak negative effect on the t-statistics, the effect only contributes $10 \%$ of the average t-statistic. The remainder of the t-statistics are attributable to the time difference. The second alternative explanation is addressed by excluding the top quartile of the grade distribution for each of the 194 cards. We find the remaining three quartiles still exhibit a significant decline in the mean grade for $95 \%$ of the 194 cards, rejecting the second alternative explanation. Further robustness tests are carried out to account for the fact that PSA was the only grader in 1997 but not the only grader in 2001. To this end, we supplemented the PSA grading population with the BGS and SGC grading populations for each of the 194 cards in March 2002 and re-ran the tests: these modifications did not change any of the conclusions.

Overall, the above evidence suggests that the simultaneous explosion of demand for grading services and the growth of online trading at the same time is not a coincidence. One explanation is that professional grading allowed owners of relatively high quality cards to take advantage of the transaction cost savings while credibly separating themselves from counterfeit and lower quality cards. This is perfectly consistent with the observation that two thirds of the online

\footnotetext{
${ }^{28}$ All three of these tests were run as one tailed tests at the $95 \%$ confidence level.
} 
auctions completed during our market watch period involved graded cards, and explains how grading service demand could expand while retail markets shrank. The growth of demand for professional grading services is inconsistent, however, with a baseball popularity-driven story of retail decline; rising popularity would increase both grading demand and retail demand while falling popularity ought to result in lower demand for both. The fact that we have retail sportscard demand and professional grading demand headed in opposite directions casts doubt on whether the popularity of the sport could explain both simultaneously.

\section{Changes in Card Printing}

The model we consider in this paper represents the balance between online and retail markets for all copies of a single type of card. Since online markets expand at the expense of retail markets, card producers should make card designs well suited to online trading, which is exactly what is observed in reality.

The most striking change in the sportscard industry was the shift of product lines towards insert cards. Normally, card companies print sheets of cardboard that they cut and sell as "packs" of 10 to 15 random cards to final consumers. Companies may produce a limited number of special types of cards and randomly insert them into packs of normal cards. Some of these insert cards may use fancy manufacturing processes such as foil embossing, holographic or prismatic surfacing, or even gold leafing. Other insert cards may feature an autograph, a swatch of cloth from a game-worn jersey, or a wood shaving from a player's bat. In addition to these special features, the value of insert cards is also driven by their extreme rarity and how easily a lucky pack buyer can find someone to sell his insert card to. ${ }^{29}$

Based on these features, we now provide a logic that links the growth of insert card types to the rise of online trading. Before eBay, search costs in the retail market are relatively high, restricting the liquidity of the market. The illiquid market reduces the expected value of buying a pack and also discourages the printing companies from printing high value insert cards. After eBay, the increased liquidity of the online market allows an individual who draws an insert card to find a buyer more easily, raising the expected value of buying a pack. High value in the online market is further assured by the existence of professional grading, which allows the insert card

\footnotetext{
${ }^{29}$ For example, insert cards are usually limited to several hundred copies. In some extreme cases, cards are serial numbered and limited to single digit production runs. For comparison, ordinary non-insert card print runs are usually in the hundreds of thousands.
} 
owner to avoid questions of authenticity. As a consequence, the printing company will be able to capture all of these gains by printing more insert cards and then increasing the price of a pack in the primary market. To avoid depressing the secondary market value of insert cards, which depend on scarcity, the printer will produce many unique insert card designs and restrict the quantity of each design. This strategy will be pursued until the marginal gains from secondary market rent extraction equals the marginal losses from lower primary market sales.

This logic is confirmed by the explosion of the types of insert cards introduced since the growth of online trading in eBay. As shown in Table 2, from 1990 to 1996, the combined total of insert card types per year from all 5 card printers was stable and between 5 and 18. Then in 1997 and 1998 during the early growth of eBay, insert card types per year jumped to 33 and then 46. Following eBay's IPO, insert card types increased to 110 in 1999, 164 in 2000, and finally 724 in 2001 . Today, every printer advertises the types of inserts contained in a set as the main feature of the set and Beckett frequently features stories of lucky collectors who happen to draw the rarest of insert cards.

Two examples are illustrative of this phenomenon. One local shop owner in Dale City, VA told us that a customer received a Grover Cleveland Alexander autographed card whose production was limited to one copy. The customer went online immediately and sold the card for $\$ 13,000$. 30 Another shop owner in Halethorpe, MD informed us that about $20 \%$ of his business was conducted online, and these were almost exclusively sales of insert cards on eBay.

\section{Conclusion}

Every new method of trade offers a new opportunity that all economic agents will explore for their own interests. This paper presents a case study confirming this intuition.

The advent of the Internet provides a coherent explanation for all changes in sportscard trading: (1) some online buyers naively believe in meaningless claims of quality thus attracting fraudulent sellers to the online ungraded sector (Jin \& Kato 2004); (2) sophisticated buyers understand the online information problem, resulting in more reliance on grading services and worse quality of ungraded cards online (as compared to offline); (3) retail stores and card shows decline in the 1990s, due to their disadvantage in transaction costs; (3) most surviving retailers stay offline and deal mainly with ungraded cards, as their expertise in identifying good quality

\footnotetext{
${ }^{30}$ See Beckett Baseball Cards Monthly, March 2002 on p.108 "One of One Fine Day." The article mentions the sale price, but not that it was sold online.
} 
cards is most valuable there; (4) grading services undergo substantial growth because grading helps overcome the worsened information asymmetry between buyers and sellers online; and finally (5) card printers switch towards short printed cards suitable for exploiting the advantages of online trading.

This interpretation is subject to an obvious caveat: adoption of Internet trading is a oneshot event, and therefore it is impossible to separate the causal effect of the Internet from other market changes over time such as changes in baseball popularity or collector demographics. We argue that these alternative explanations may succeed in explaining one empirical fact, but they cannot account for all of them in any coherent way. Consider baseball's popularity as a sport. It is possible that baseball's popularity declined over time while the Internet took off, and that negative demand shock for sportscards could account for the decline in retail markets. However, at the same time card grading demand soared, and people were willing to take greater chances by paying to grade ever-lower quality cards. Card printing companies in fact expanded to not only more but higher quality sets of cards. Conversely, if sportscard demand experienced a positive shock ${ }^{31}$, we would expect to see such an expansion in grading and card printing activities, but the retail shrinkage would not make sense. We believe that while the Internet may not have been the sole cause of the phenomena observed in this study, the fact it can explain every observed fact in a coherent way suggests it must have played a very important role.

The case study on online/offline trading of sportscards provides two lessons that may be useful for understanding the impact of other new markets. A new market, generated by either a new trading method (say mail-order) or a product innovation (say cellular phone), is likely to have both advantages and disadvantages over the existing market. It is the trade off between these advantages and disadvantages that drives different agents to behave differently thus fostering the coexistence of old and new markets.

Moreover, a new market not only affects economic agents that face the choice between new and old markets, but also influences those who support the needs of such economic agents. The existing empirical studies on online trading primarily focus on buyers' choice of market or sellers' pricing strategy (see footnotes 2 and 3 for detailed citations). This paper shows that the advent of the Internet may have contributed to changes in traditional retailing, professional grading services, and primary manufacturer decisions. These indirect effects are often overlooked because they deal with economic agents who are not actually participating in the new market segment: they are players in rival markets competing for "thickness," as well as upstream and downstream industries. From a general equilibrium point of view, it is important to consider

\footnotetext{
${ }^{31}$ For instance, good prevailing economic conditions.
} 
how supply meets demand in both old and new markets, and how the separation of old and new markets affect supporting industries.

\section{References}

Akerlof, George (1970): "The Market for 'Lemons': Quality Uncertainty and the Market Mechanism," Quarterly Journal of Economics 222: 488-500.

Bajari, Patrick and Ali Hortacsu (2003): "The Winner's Curse, Reserve Prices and Endogenous Entry: Empirical Insights from eBay Auctions," Rand Journal of Economics, Summer.

Bajari, Patrick and Ali Hortacsu (forthcoming): "Economic Insights from Internet Auctions" Journal of Economic Literature.

Bresnahan, Tim and Peter Reiss (1991): "Entry and Competition in Concentrated Markets, Journal of Political Economy 99 (October): 977-1009.

Brown, Jeffrey R. and Austan Goolsbee (2002): "Does the Internet Make Markets More Competitive? Evidence from the Life Insurance Industry," Journal of Political Economy 110(3): 481-507.

Chevalier, Judith and Austan Goolsbee (forthcoming): "Measuring Prices and Price Competition online: Amazon vs. Barnes and Noble" Quantitative Marketing and Economics I(2).

Clay, Karen; R. Krishnan and E. Wolff: "Prices and Price Dispersion on the Web: Evidence from the Online Book Industry," Journal of Industrial Economics Dec. 2001, Vol.49: 521-39.

Ellison, Glenn and Sara Fisher Ellison (2001): "Search, Obfuscation, and Price Elasticities on the Internet," MIT working paper.

Ellison, Glenn and Sara Fisher Ellison (2003): "Tax Sensitivity and Home State Preferences in Internet Purchasing" MIT working paper.

Genesove, David (1993): "Adverse Selection in the Wholesale Used Car Market," The Journal of Political Economy Volume 101, Issue 4 (Aug. 1993) 664-665.

Goolsbee, Austan (2000): "In a World Without Borders: The Impact of Taxes on Internet Commerce," The Quarterly Journal of Economics May 2000.

Goolsbee, Austan (2001): "Competition in the Computer Industry: Online Versus Retail," Journal of Industrial Economics Dec. 2001, Vol 49: 561-76.

Jin, Ginger Z. and Andrew Kato (2004): "Consumer Frauds and the Uninformed: Evidence Fron an Online Field Experiment" University of Maryland Working Paper. 
Jin, Ginger Z., Andrew Kato and John List (2004): "Evolution of Professional Certification Markets: Evidence from Field Experiments" University of Maryland Working Paper.

Lucking-Reiley, David (2000): "Auctions on the Internet: What's being auctioned and how?" Journal of Industrial Economics 48(2): 227-252.

Melnik, Mikhail I. and James Alm (2002), "Does a Seller's eCommerce Reputation Matter?" Journal of Industrial Economics 50(3): 337-349.

Resnick, Paul and Richard Zeckhauser (2002): "Trust Among Strangers in Interent Transactions: Empirical Analysis of eBay's Reputation System," The Economics of the Internet and E-Commerce M.R. Bayes, eds. Amsterdam, Elservier Science, 11: 127-157.

Rysman, Mark (2004): "Competition Between Networks: A Study of the Market for Yellow Pages" Review of Economic Studies 71(2): 483-512.

Scott Morton, Fiona; J.S. Risso and F.Zettelmeyer (2001a): "Internet Car Retailing," Journal of Industrial Economics, Vol. XLIX, No. 4 (December 2001).

Scott Morton, Fiona; J.S. Risso and F. Zettelmeyer (forthcoming): "The Effect of the Internet on Car Prices for Women and Minorities" The Journal of Quantitative Marketing and Economics.

Scott Morton, Fiona; J.S. Risso and F.Zettelmeyer (2004):" Cowboys or Cowards: Why are Internet Car Prices Lower?" Haas School Univ. of California Berkeley Marketing Research Working Paper No. $01-1$.

Zettelmeyer, Florian (2000): "Expanding to the Internet: Pricing and Communications Strategies When Firms Compete on Multiple Channels," (2000), Journal of Marketing Research, Vol. 37(3), pp. 292-308. 
Table 1: Experimental Results Summary - Price and Quality

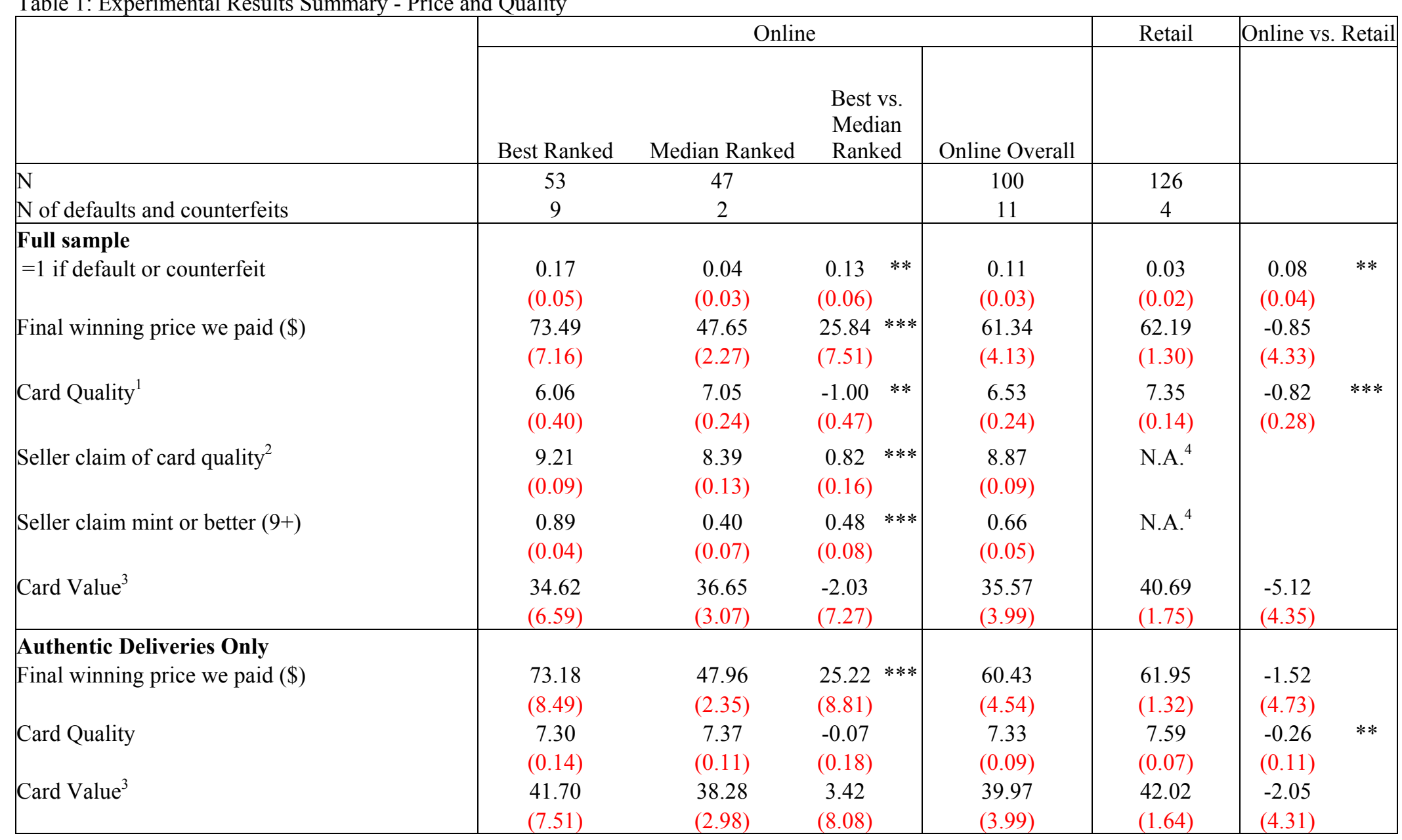

Note: In parentheses are standard errors of sample means. ${ }^{* *} \mathrm{p}<0.01,{ }^{* *} \mathrm{p}<0.05,{ }^{*} \mathrm{p}<0.1$. (1) Defaults and counterfeits are coded as zero quality. (2) Conditional on cards that have any seller claims. (3) Card value is calculated based on Beckett low book prices. (4) Retail dealers rarely make any quality claims for ungraded cards. 
Table 2: Explosion of Insert Cards from 1983 to 2001

\begin{tabular}{|c|c|c|c|}
\hline Year & $\begin{array}{c}\text { Total Number of Sets Offered by All } \\
\text { Printers }\end{array}$ & Total Number of Regular Sets & Total Number of Insert Card Subsets \\
\hline 1983 & 4 & 4 & 0 \\
1986 & 9 & 6 & 3 \\
1989 & 19 & 13 & 6 \\
1992 & 28 & 16 & 12 \\
1995 & 26 & 21 & 5 \\
1996 & 44 & 26 & 33 \\
1997 & 61 & 28 & 46 \\
1998 & 82 & 36 & 110 \\
1999 & 153 & 43 & 164 \\
2000 & 230 & 66 & 724 \\
\hline
\end{tabular}

Figure 1: Timelines

\begin{tabular}{|c|c|c|}
\hline & Printing, trading and grading of baseball cards & The Internet \\
\hline 1952 & Topps bubble gum company became the first and the only dedicated card printer. & \\
\hline $1960 \mathrm{~s}$ & $\begin{array}{l}\text { Card collection was viewed as kid activity although a large number of baby boomers } \\
\text { kept the hobby after adolescence. }\end{array}$ & $\begin{array}{l}\text { In 1969, the first wide-area network connected four } \\
\text { universities under ARPANET. }\end{array}$ \\
\hline Early 1970s & $\begin{array}{l}\text { A few card dealers began to set up retail shops and card shows started to emerge in } \\
\text { large cities. }\end{array}$ & \\
\hline 1981 & $\begin{array}{l}\text { Two new printers, Donruss and Fleer, appeared. Error and variation cards became } \\
\text { the first kind of rare cards. Collectors realized that baseball cards could be traded as } \\
\text { valuable commodities. }\end{array}$ & \\
\hline 1984-1986 & $\begin{array}{l}\text { Donruss and Fleer began to limit production and distribution to create a perceived } \\
\text { scarcity of sets. Beckett Baseball Cards Monthly was first published in } 1984 \text {. }\end{array}$ & $\begin{array}{l}\text { In the mid 1980s, the Internet was born as a loose collection } \\
\text { of networks under ARPANET. }\end{array}$ \\
\hline 1989 & New printer Upper Deck issued the first high quality set. & \\
\hline 1990 & Upper Deck introduced insert cards. & \\
\hline $1991-1993$ & $\begin{array}{l}\text { Professional Sports Authenticator (PSA) started providing professional grading } \\
\text { services for baseball cards in 1991. }\end{array}$ & $\begin{array}{l}\text { World Wide Web (WWW) was born in } 1991 \text { and graphical } \\
\text { browsing of WWW became feasible in } 1993 .\end{array}$ \\
\hline 1994 & MLB players strike canceled baseball season. & \\
\hline 1995-1997 & $\begin{array}{l}\text { All printers combined produced } 18 \text { types of insert cards in } 1996 \text {. After } 7 \text { years of } \\
\text { operation, the PSA graded population of } 194 \text { popular baseball cards reached } 40,723 \\
\text { by the end of } 1997 \text {. }\end{array}$ & $\begin{array}{l}\text { Internet access became widely available to the public. } \\
\text { Netscape went public on August } 8,1995 \text {. Yahoo! went } \\
\text { public on April } 12,1996 \text {. }\end{array}$ \\
\hline 1998 & The number of types of insert cards reached 46. & eBay went public on September, 24, 1998. \\
\hline 1999 & Insert card types increased to 110 . The parent company of PSA went public. & \\
\hline 2001 & $\begin{array}{l}\text { Insert card types exploded to } 724 \text {. For the same } 194 \text { popular baseball cards, the PSA } \\
\text { grading population increased to } 316,292 \text { copies by the end of } 2001 \text {. }\end{array}$ & \\
\hline
\end{tabular}


Figure 2: Examples of Ungraded and Graded Baseball Cards

Ungraded - 1989 Upper Deck \#1 Ken Griffey Jr. (Rookie)

Graded - 1985 Topps \#401 Mark McGwire (Rookie)
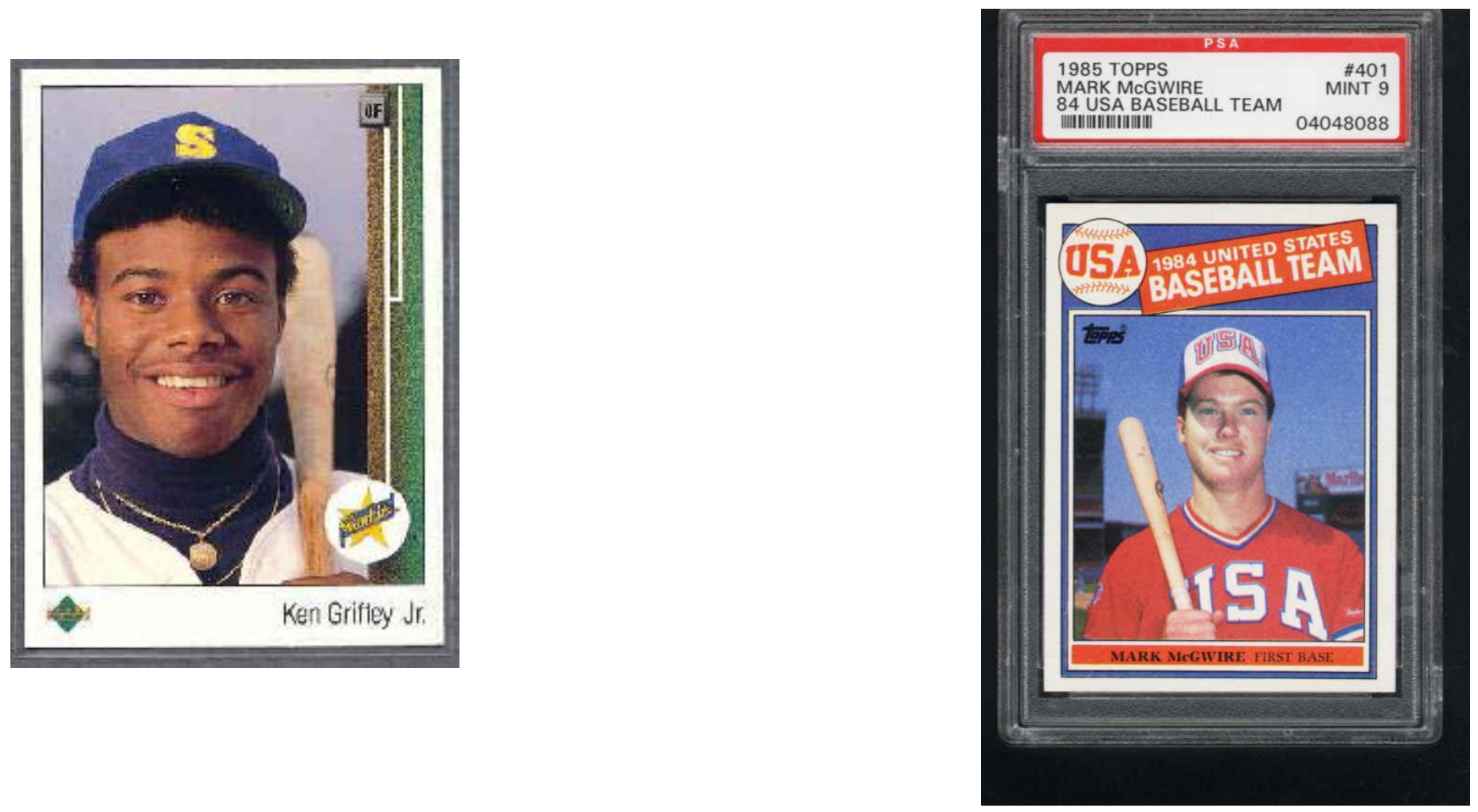
Figure 3: Predictions from the Model

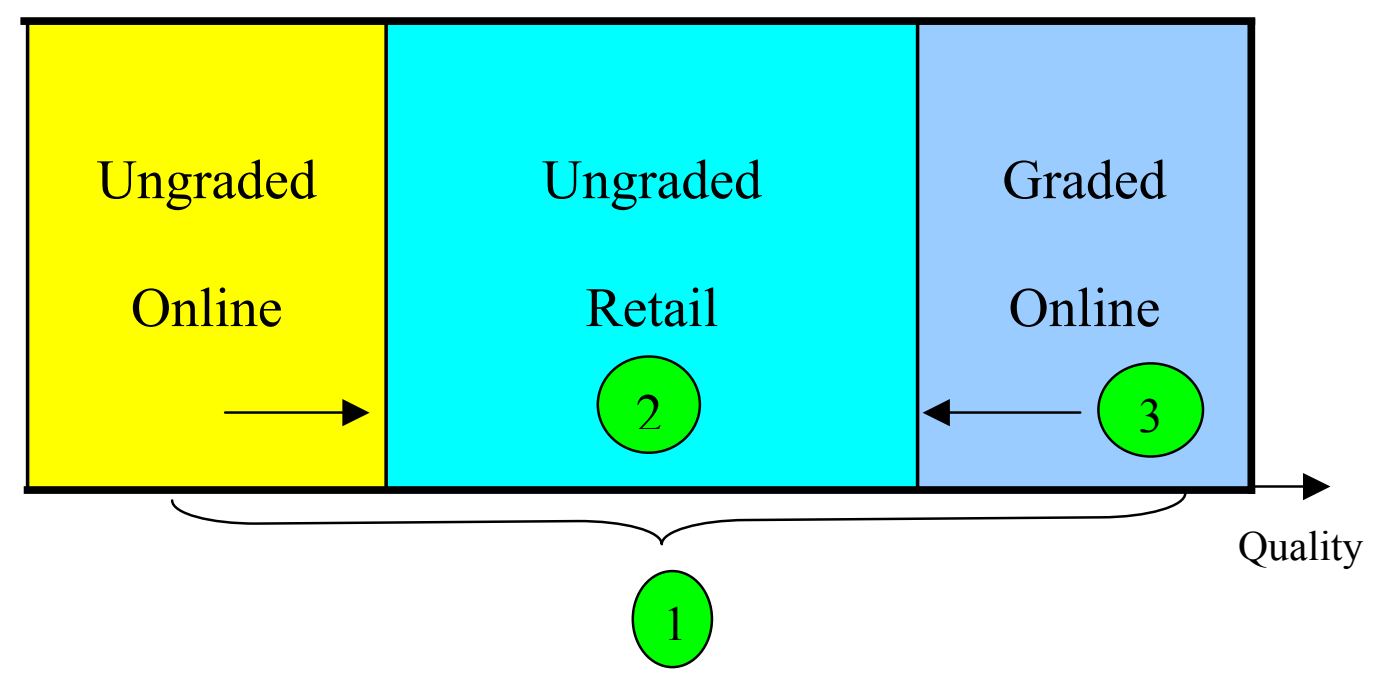

Figure 4: Grade Distribution of Real Purchases

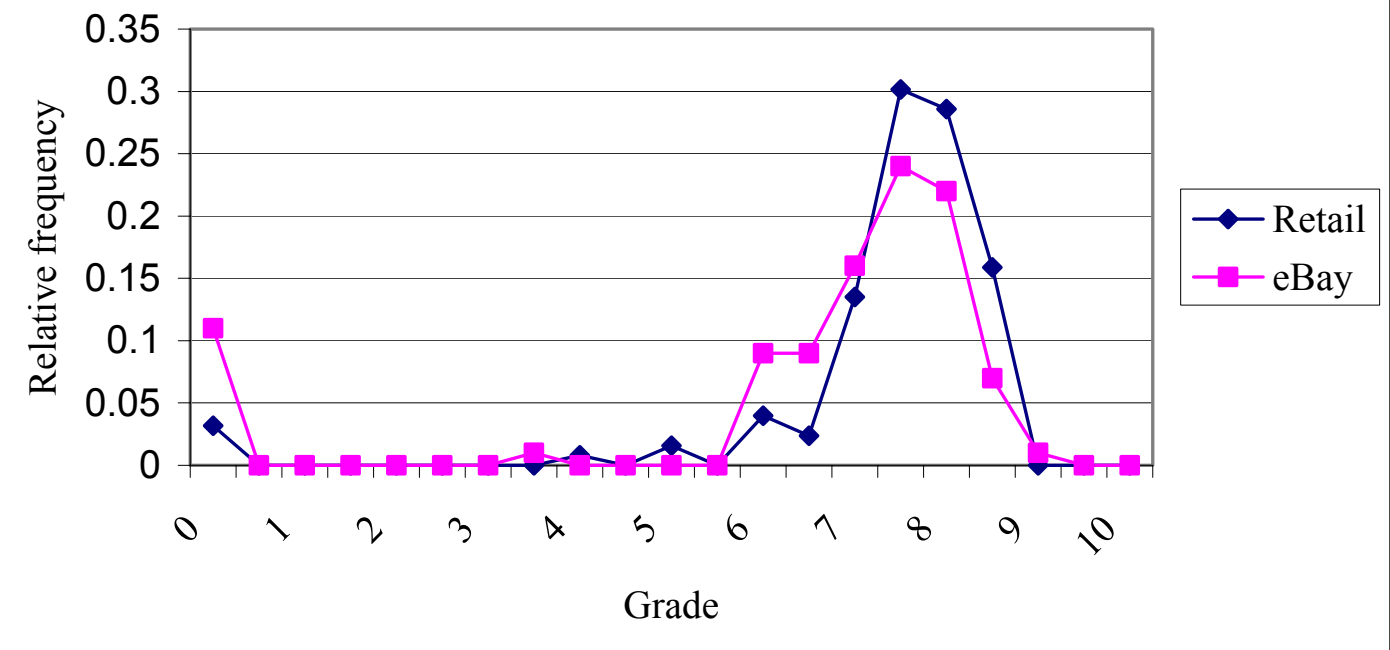


Figure 5

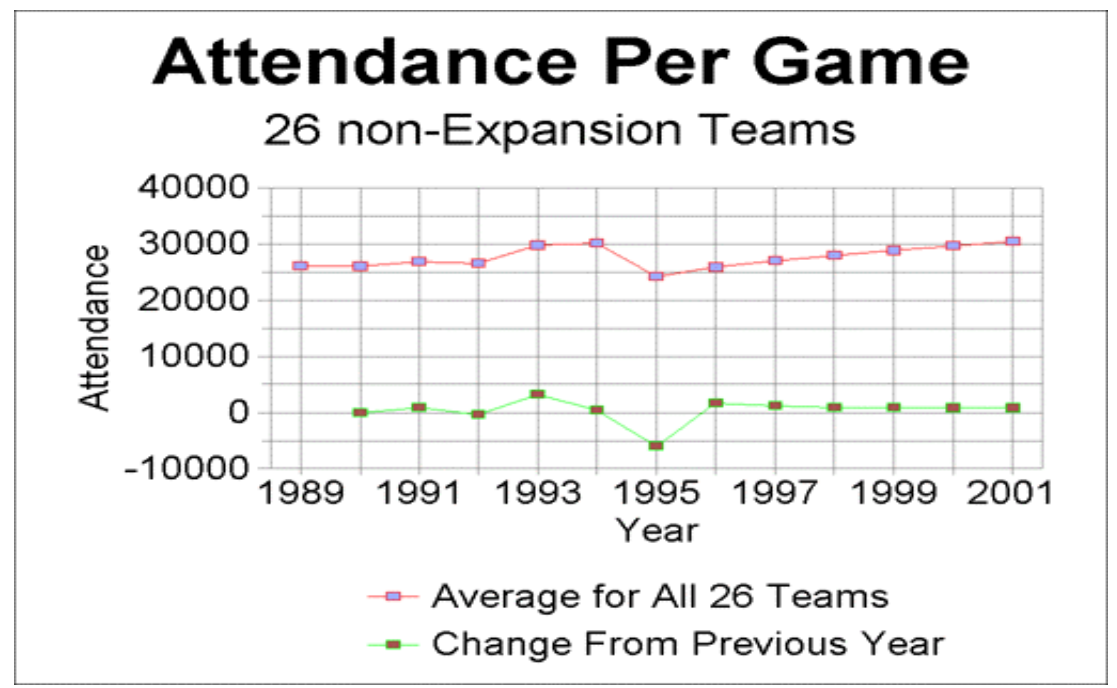

Figure 6

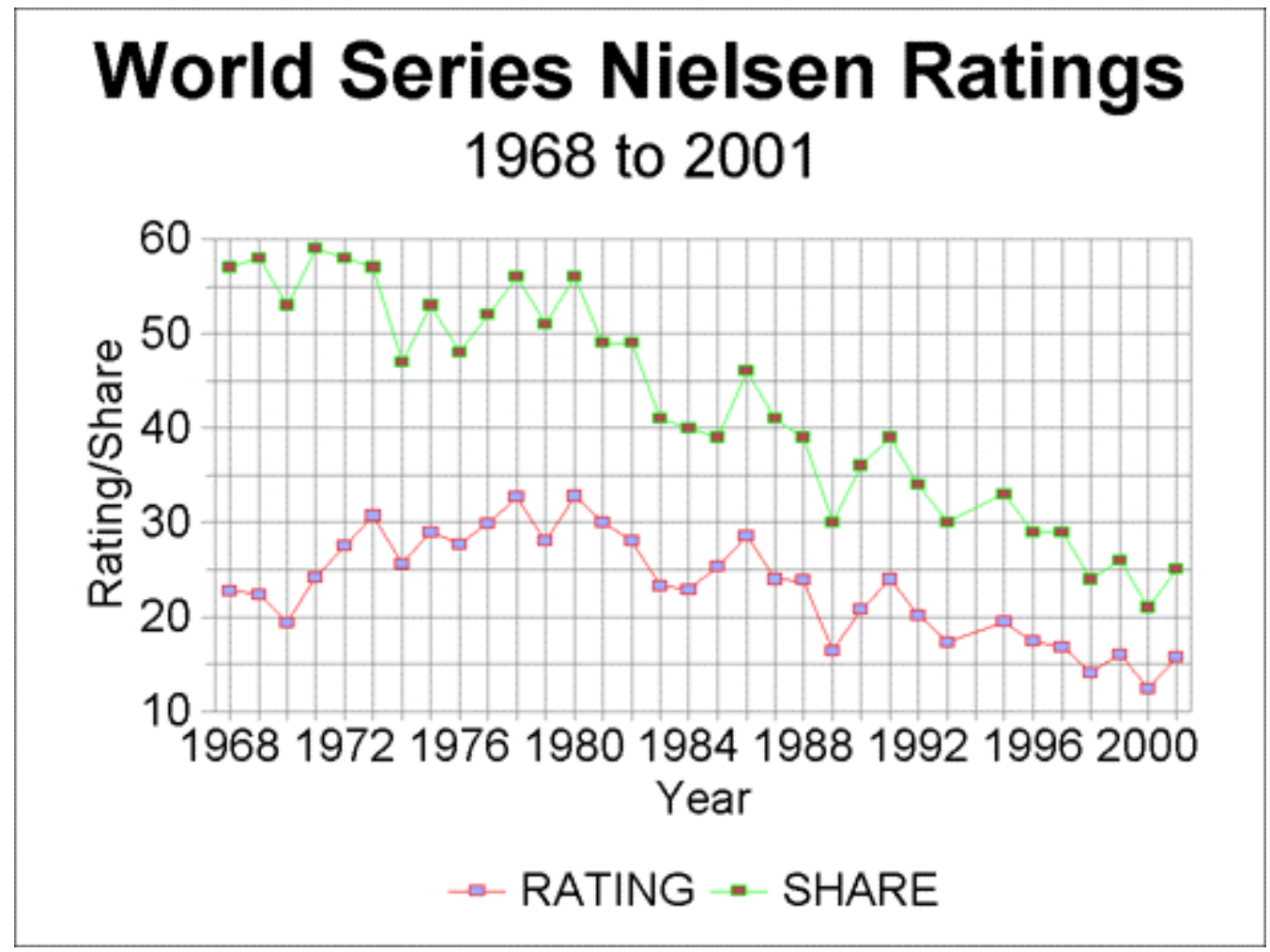



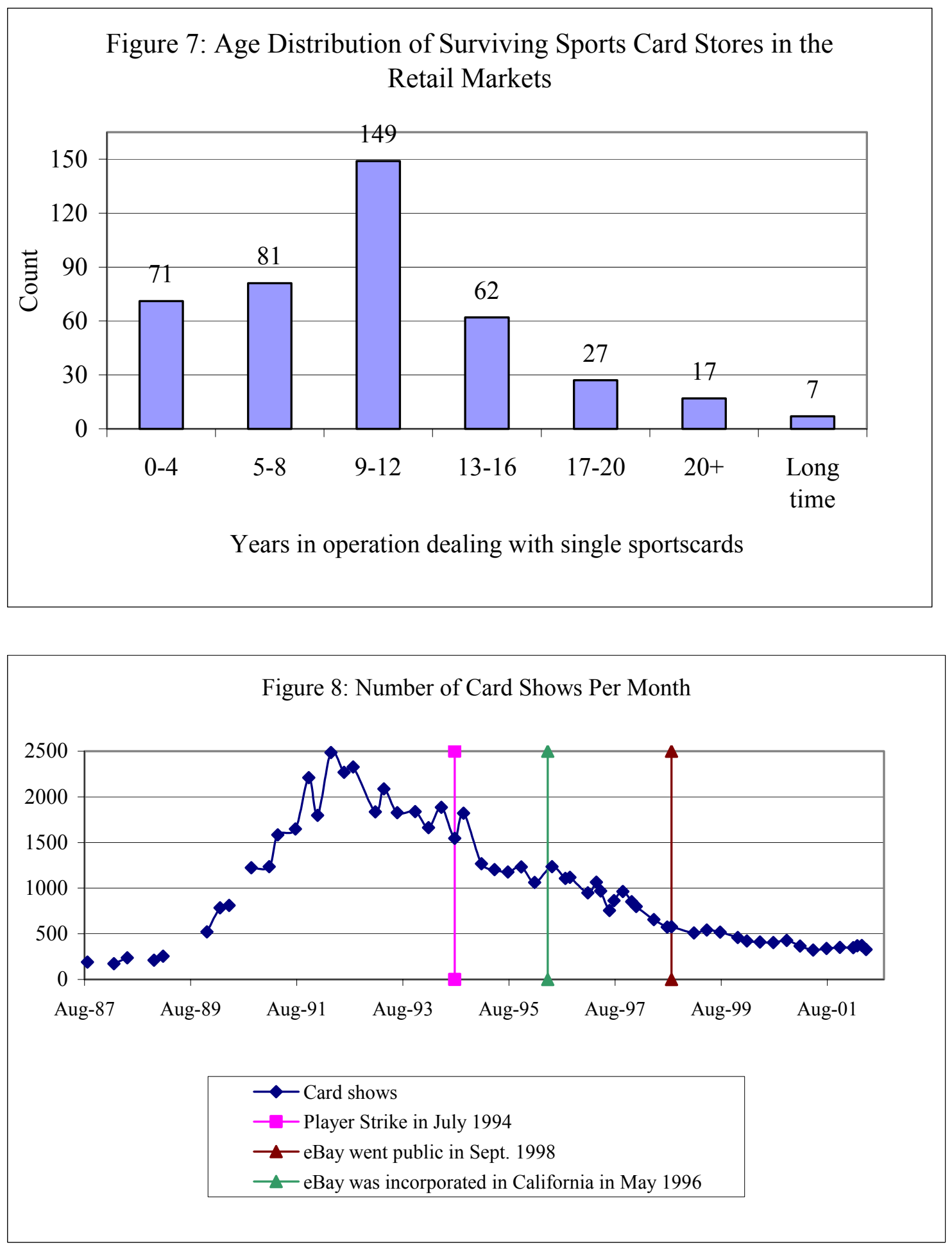


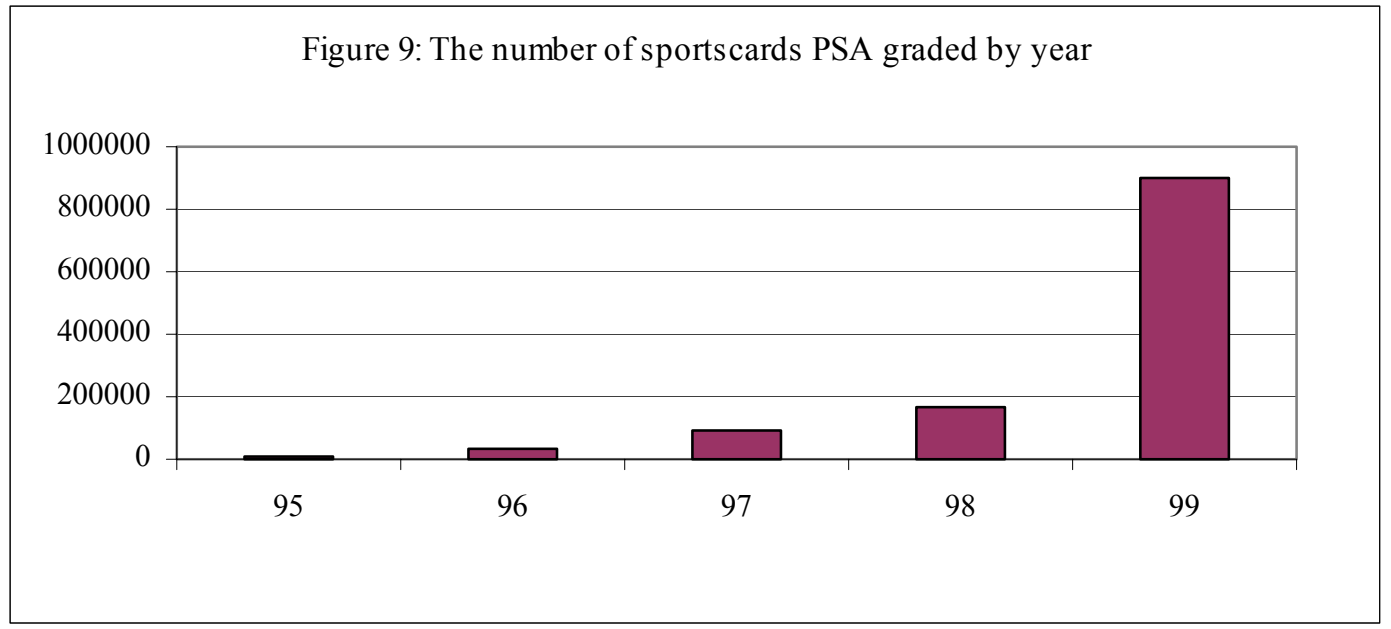

Source: Prospectus of Collectors Universe Inc. (PSA's Parent), Nov. 1999.

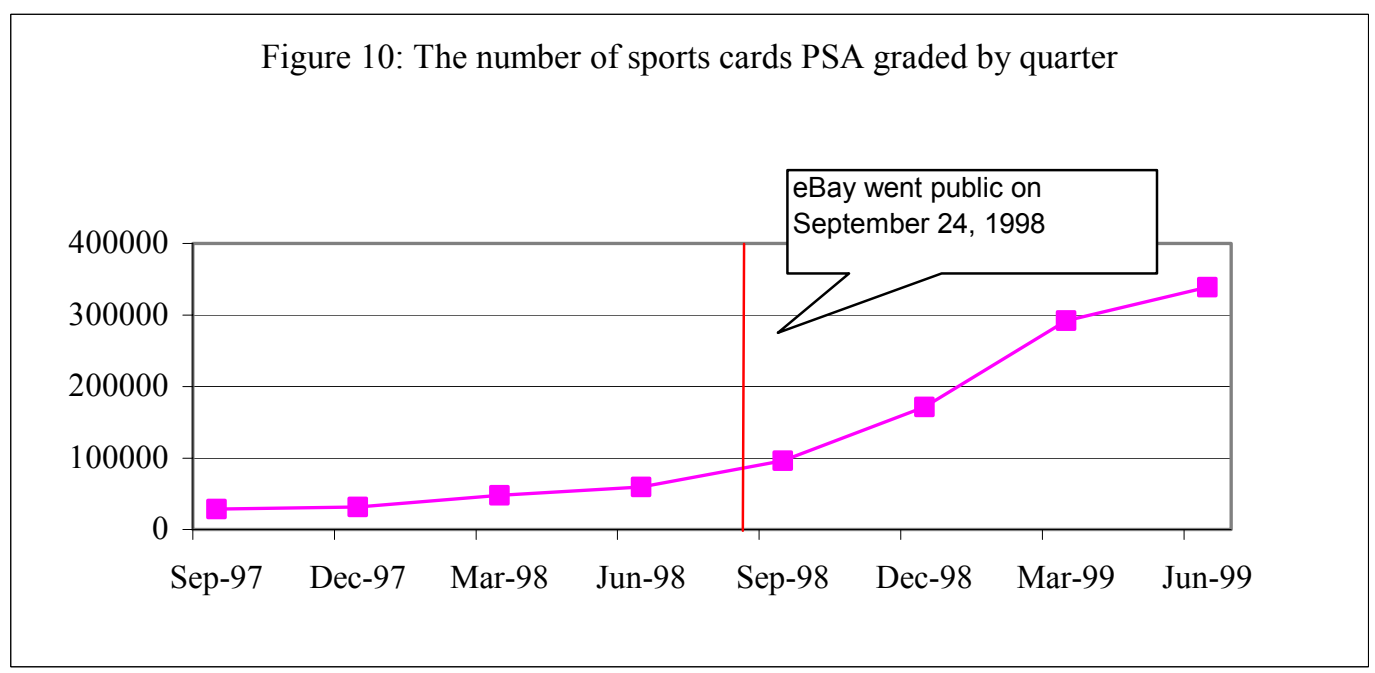

Source: Prospectus of Collectors Universe Inc. (PSA's Parent), Nov. 1999.

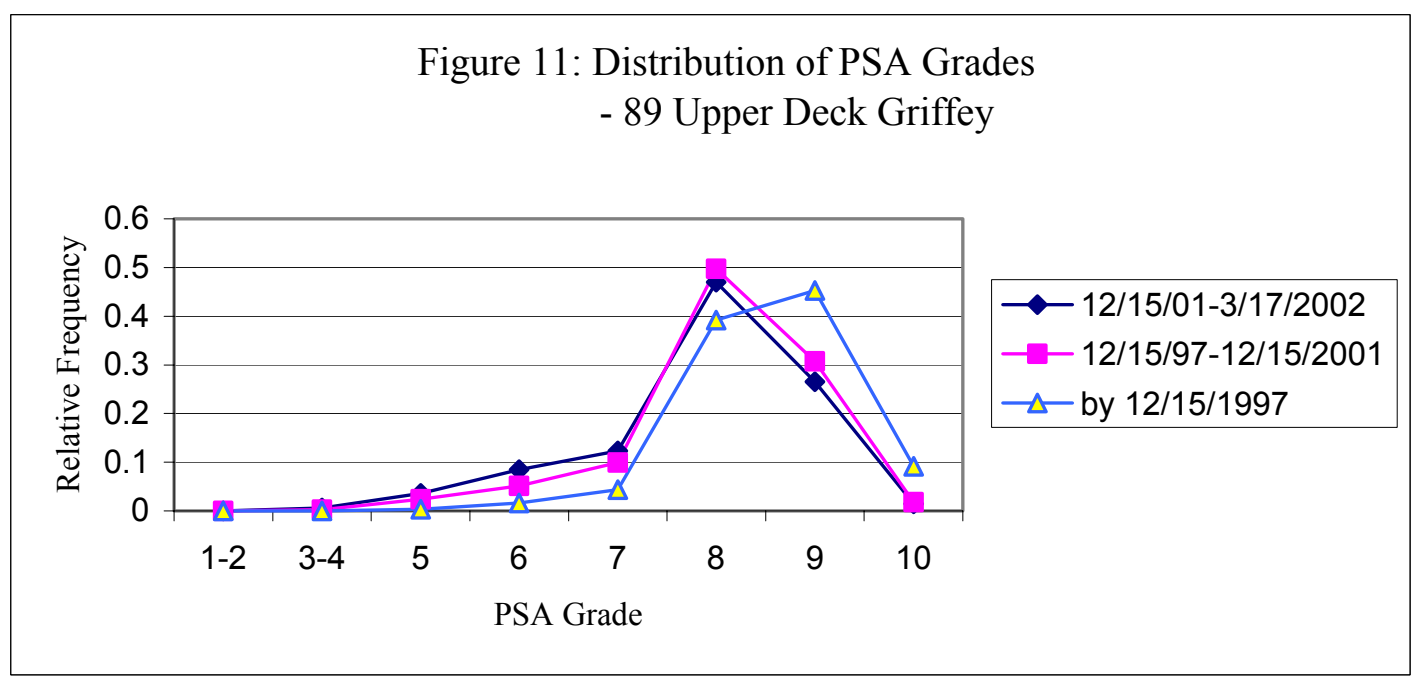

Source: PSA population report, as of 12/15/1997, 12/15/2001/ and 03/17/2002. 